\title{
IMPLEMENTASI KEBIJAKAN UPAH MINIMUM KABUPATEN (UMK) DAN PENGARUHNYA TERHADAP KESEJAHTERAAN MASYARAKAT (Studi Pada Kabupaten Kebumen)
}

\author{
HENDRAWAN PRASETYO, S.Sos, M.Si. \\ Program Studi Manajemen \\ STIE Putra Bangsa Kebumen \\ hendrawanprasetyo@yahoo.com
}

\begin{abstract}
Almost the average company in Kebumen Regency has applied salary payment of employees in accordance with the provisions of MSEs, although in implementation is not one hundred percent. Although Kebumen District Government has set District Minimum Wage (MSE) in 2017 amounting to Rp 1,433,900.00, but there are still many employers / companies that pay salaries under the MSEs. The relations of workers and employers actually need each other. Workers expect the fulfillment of the necessities of life and the entrepreneur seeks to maintain the survival of his company. Without employers, workers find it difficult to sustain their lives, whereas unemployed workers will not be able to continue their business. So it needs a good relationship between the two, the existence of mutual understanding. Employers need to understand the needs of the workers, and the workers understand the company's ability to pay wages. The purpose of this study is to find out how the implementation of District Minimum Wage policy and its impact on community welfare in Kebumen District. The type of this research is qualitative research, taking the data source using the technique of "purposive sampling" with the number of informants as many as 11 people including from the elements of local government that is the Office of Manpower and Cooperative SME Kebumen Regency, private entrepreneurs in Kebumen District, and employees of private companies in Kebumen. Data collection in this research is done through observation, documentation and in-depth interview. Data analysis techniques in this study is interactive model analysis, including four components of data collection, data reduction, data presentation and conclusion or verification. Theories used are theories of public policy, policy implementation and wages. The results of this study found that almost most companies in Kebumen District have paid employee salaries according to MSEs, although there are still companies that have not been able to meet the payroll of employees according to the MSES. Some companies studied do not experience obstacles in the implementation of MSE in accordance with the established, but if the company has problems in terms of implementing payroll employees according to MSEs there is a mechanism of deferring payment. The role of local government in the implementation of MSE is needed in terms of socialization and coaching and know the problems that occur in the company or labor in the scope of Kebumen. In terms of achieving the welfare of workers, the company should be able to provide salaries in accordance with the Minimum Wage and supplemented with the provision of various benefits in order to create the welfare of workers in particular and society in general.
\end{abstract}

Keywords: policy implementation, workers, company, welfare, minimum wage

\section{PENDAHULUAN}

Jumlah tenaga kerja di Indonesia mengalami peningkatan dari tahun ke tahun, namun peningkatan jumlah tenaga kerja tersebut tidak disertai dengan adanya peningkatan jumlah lapangan pekerjaan. Hal tersebut mengakibatkan adanya ketidak seimbangan antara jumlah lapangan kerja dengan jumlah pencari kerja, sehingga angka pengangguran semakin bertambah. Sehingga posisi tawar calon pekerja menjadi rendah, terutama dalam hal pengupahan. Bagi pengusaha, supaya biaya produksi tidak meningkat, maka biaya tenaga kerja ditekan 
dengan cara mencari buruh yang mau dibayar sesuai dengan kemampuan perusahaan.

Hubungan pekerja dan pengusaha sebenarnya saling membutuhkan. Pekerja bertujuan untuk terpenuhinya kebutuhan hidup dan pengusaha supaya menjaga kelangsungan hidup perusahaannya. Tanpa pengusaha, pekerja sulit mempertahankan hidupnya, sedangkan tanpa pekerja, pengusaha tidak akan dapat meneruskan bisnisnya. Sehingga diperlukannya hubungan yang baik antar keduanya, adanya saling pengertian. Pengusaha perlu mengerti mengenai kebutuhan buruh, dan pekerja mengerti kemampuan perusahaan dalam membayar upah.

Pemerintah diperlukan untuk menjaga supaya hubungan keduanya berjalan seimbang. Tidak ada pihak

yang merasa dirugikan maupun diperlakukan secara tidak adil. Permasalahan di bidang ketenagakerjaan yang kerap

terjadi adalah mengenai pengupahan. Kaitannya dengan UMK, banyak perusahaan yang sudah membayar upah sesuai dengan UMK maupun bahkan di atas UMK, namun masih ada perusahaan yang membayar upah di bawah standar UMK.
Kebijakan publik merupakan arah tindakan yang mempunyai maksud yang ditetapkan oleh seorang aktor atau sejumlah aktor dalam mengatasi suatu masalah atau suatu persoalan (Winarno, 2002:16). Dalam praktiknya kebijakan publik baiknya harus mengandung unsur-unsur sebagai berikut (Widodo, 2001:190). Dalam tahap implementasi kebijakan akan menemukan dampak dan kinerja dari kebijakan tersebut. Disini akan ditemukan apakah kebijakan yang dibuat mencapai tujuan yang diharapkan atau tidak.

\section{IDENTIFIKASI MASALAH}

1. Bagaimana implementasi Upah Minimum Kabupaten (UMK), apakah perusahaan sudah membayar karyawan sesuai dengan UMK yang telah ditetapkan?

2. Kendala apa yang dihadapi oleh pengusaha untuk membayar gaji karyawan sesuai UMK yang telah ditetapkan.

3. Bagaimana peran pemerintah dalam mengawasi pelaksanaan penggajian karyawan sesuai dengan UMK di Kabupaten Kebumen?

4. Apakah UMK yang ditetapkan sudah dapat mensejahterakan masyarakat?

\section{KERANGKA PIKIR}

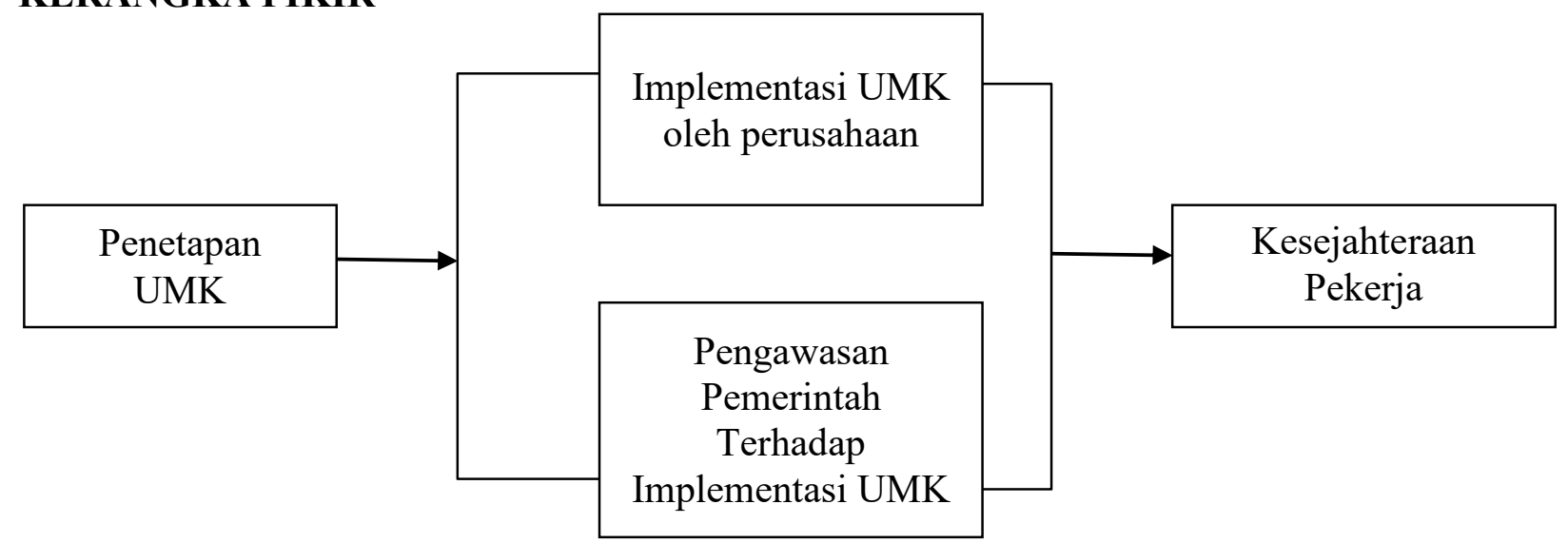

\section{METODE PENELITIAN}

Jenis penelitian ini merupakan penelitian kualitatif. Penelitian kualitatif bertolak dari filsafat konstruktivisme yang berasumsi bahwa kenyataan itu berdimensi jamak, interaktif dan suatu pertukaran pengalaman sosial yang diinterpretasikan oleh individu-individu. Penelitian kualitatif ditujukan untuk memahami fenomena-fenomena sosial dari sudut perspektif partisipan. Partisipan adalah orang-orang yang 
diajak berwawancara, diobservasi, diminta memberikan data, pendapat, pemikiran, persepsinya (Sukmadinata, 2006: 94).

Penelitian ini menggunakan pendekatan kualitatif, yaitu berusaha mendapatkan informasi yang selengkap mungkin mengenai dampak implementasi kebijakan UMK Informasi yang digali lewat wawancara mendalam terhadap informan yang terdiri dari buruh, pengusaha dan pemerintah. Proses observasi dan wawancara mendalam bersifat sangat utama dalam pengumpulan data. Dalam penelitian ini pendekatan yang dilakukan adalah melalui pendekatan kualitatif. Artinya data yang dikumpulkan bukan berupa angka-angka, melainkan data tersebut berasal dari naskah wawancara, catatan lapangan, dokumen pribadi, catatan memo, dan dokumen resmi lainnya. Sehingga yang menjadi tujuan dari penelitian kualitatif ini adalah ingin menggambarkan realita empirik di balik fenomena secara mendalam, rinci dan tuntas. Oleh karena itu penggunaan pendekatan kualitatif dalam penelitian ini adalah dengan mencocokkan antara realita empiric dengan teori yang berlaku dengan menggunakan metode deskriptif.

Dalam penelitian ini, penulisan difokuskan pada persoalan-persoalan yang berkaitan dengan dampak yang ditimbulkan dengan adanya implementasi kebijakan UMK terhadap kesejahteraan masyarakat.

Teknik pengumpulan data yang dilakukan dalam penelitian ini adalah sebagai berikut:

1. Observasi

Dalam penelitian ini teknik observasi digunakan untuk memperkuat data, observasi dilakukan dengan mengamati secara langsung

2. Wawancara

Wawancara yang dilakukan dengan dua bentuk, yaitu wawancara terstruktur (dilakukan melalui pertanyaan-pertanyaan yang telah disiapkan sesuai dengan permasalahan yang akan diteliti), dan wawancara tak terstruktur (wawancara dilakukan apabila adanya jawaban berkembang diluar pertanyaan-pertanyaan terstruktur namun tidak terlepas dari permasalahan penelitian) (Nasution,
2006:72). Dalam penelitian ini wawancara dipergunakan untuk mengadakan komunikasi dengan pihak-pihak terkait atau subjek penelitian, antara lain dalam rangka memperoleh penjelasan atau informasi tentang hal-hal yang belum tercantum dalam observasi dan dokumentasi. Dalam penelitian ini wawancara dilakukan oleh peneliti dengan bantuan instrument wawancara yang berupa panduan wawancara/interview guide sehingga pertanyaan yang diajukan dalam wawancara menjadi lebih terstruktur dan sesuai dengan permasalahan yang ingin diketahui oleh peneliti. Wawancara dilakukan tidak dalam satu waktu, namun beberapa kali peneliti mendatangi informan sehingga data dan informasi yang dikumpulkan menjadi lebih akurat dan lengkap karena kekurangan data/informasi dapat ditanyakan pada waktu yang berbeda dengan situasi yang berbeda.

3. Dokumentasi

Analisis dokumen dilakukan untuk mengumpulkan data yang bersumber dari dokumen-dokumen yang ada yang berasal dari data skunder..

Pengambilan sumber data penelitian ini menggunakan teknik "purpose sampling" yaitu pengambilan sampel didasarkan pada pilihan penelitian tentang aspek apa dan siapa yang dijadikan fokus pada saat situasi tertentu dan saat ini terus-menerus sepanjang penelitian, sampling bersifat purpossive yaitu tergantung pada tujuan fokus suatusaat (Nasution, 2006: 29). Subjek penelitian adalah peneliti sendiri, sedangkan informan yang digunakan untuk menggali data melalui wawancara terdiri dari pemerintah daerah (Dinas Tenaga Kerja Koperasi dan UKM) 3 orang, karyawan perusahaan 5 orang, pengusaha 3 orang sehingga total informan dalam penelitian ini berjumlah 11 orang.

\section{HASIL DAN PEMBAHASAN}

Berdasarkan hasil wawancara yang telah dilakukan di Kabupaten Kebumen hampir ratarata sudah menerapkan pembayaran gaji karyawan sesuai dengan ketentuan UMK, meskipun belum seratus persen. Meski 
Pemerintah Kabupaten Kebumen telah menetapkan Upah Minimum Kabupaten (UMK) tahun 2017 sebesar Rp 1.433.900, namun masih banyak pengusaha yang membayar gaji pegawainya dibawah UMK tersebut. Masih banyak perusahaan di Kabupaten Kebumen yang belum memberikan upah pekerja sesuai UMK. UMK Kebumen tahun 2017 merupakan yang terendah di daerah Jawa Tengah bagian selatan. UMK Kabupaten Kebumen tahun 2017 sebesar Rp 1.433.900, lebih rendah dari Cilacap yang sebesar Rp 1.693.698, Kabupaten Banyumas Rp 1.461.400, dan Kabupaten Purworejo sebesar Rp 1.445 .000

\section{Tabel 1}

\section{Daftar UMK Kabupaten/Kota} Se Jawa Tengah Tahun 2017

\begin{tabular}{clc}
\hline No & Kabupaten/Kota & $\begin{array}{c}\text { Upah } \\
\text { Minimum } \\
\text { Tahun 2017 }\end{array}$ \\
\hline 1 & Kota Semarang & $\begin{array}{c}\text { Rp. } \\
2.125 .000 .\end{array}$ \\
\hline 2 & Kabupaten Demak & $\begin{array}{c}\text { Rp. } \\
1.900 .000 .\end{array}$ \\
\hline 3 & Kabupaten Kendal & Rp. \\
& & 1.774 .867$. \\
\hline 4 & Kabupaten & Rp. \\
& Semarang & 1.745 .000$. \\
\hline 5 & Kota Salatiga & Rp. \\
& & 1.596 .844$. \\
\hline 6 & Kabupaten & Rp. \\
& Grobogan & 1.435 .000$. \\
\hline 7 & Kabupaten Blora & Rp. \\
& & 1.438 .100$. \\
\hline 8 & Kabupaten Kudus & Rp. \\
& & 1.740 .900$. \\
\hline 9 & Kabupaten Jepara & Rp. \\
& & 1.600 .000$. \\
\hline 10 & Kabupaten Pati & Rp. \\
& & 1.420 .500$. \\
\hline 11 & Kabupaten & Rp. \\
& Rembang & 1.408 .000$. \\
\hline 12 & Kabupaten Boyolali & Rp. \\
& & 1.519 .289$. \\
\hline 13 & Kota Surakarta & Rp. \\
& & 1.534 .985$. \\
\hline 14 & Kabupaten & 1.513 .000$. \\
& Sukoharjo & \\
\hline & &
\end{tabular}

\begin{tabular}{|c|c|c|}
\hline No & Kabupaten/Kota & $\begin{array}{c}\text { Upah } \\
\text { Minimum } \\
\text { Tahun } 2017\end{array}$ \\
\hline 15 & Kabupaten Sragen & $\begin{array}{c}\text { Rp. } \\
1.422 .585 \text {. }\end{array}$ \\
\hline 16 & $\begin{array}{l}\text { Kabupaten } \\
\text { Karanganyar }\end{array}$ & $\begin{array}{c}\text { Rp. } \\
1.560 .000 .\end{array}$ \\
\hline 17 & $\begin{array}{l}\text { Kabupaten } \\
\text { Wonogiri }\end{array}$ & $\begin{array}{c}\text { Rp. } \\
1.401 .000 .\end{array}$ \\
\hline 18 & Kabupaten Klaten & $\begin{array}{c}\text { Rp. } \\
1.528 .500 .\end{array}$ \\
\hline 19 & Kota Magelang & $\begin{array}{c}\text { Rp. } \\
1.453 .000 .\end{array}$ \\
\hline 20 & $\begin{array}{l}\text { Kabupaten } \\
\text { Magelang }\end{array}$ & $\begin{array}{c}\text { Rp. } \\
1.570 .000 .\end{array}$ \\
\hline 21 & $\begin{array}{l}\text { Kabupaten } \\
\text { Purworejo }\end{array}$ & $\begin{array}{c}\text { Rp. } \\
1.445 .000 .\end{array}$ \\
\hline 22 & $\begin{array}{l}\text { Kabupaten } \\
\text { Temanggung }\end{array}$ & $\begin{array}{c}\text { Rp. } \\
1.431 .500\end{array}$ \\
\hline 23 & $\begin{array}{l}\text { Kabupaten } \\
\text { Wonosobo }\end{array}$ & $\begin{array}{c}\text { Rp. } \\
1.457 .100 .\end{array}$ \\
\hline 24 & $\begin{array}{l}\text { Kabupaten } \\
\text { Kebumen }\end{array}$ & $\begin{array}{c}\text { Rp. } \\
1.433 .900 .\end{array}$ \\
\hline 25 & $\begin{array}{l}\text { Kabupaten } \\
\text { Banyumas }\end{array}$ & $\begin{array}{c}\text { Rp. } \\
1.461 .400 .\end{array}$ \\
\hline 26 & Kabupaten Cilacap & $\begin{array}{c}\text { Rp. } \\
1.693 .689 .\end{array}$ \\
\hline 27 & $\begin{array}{l}\text { Kabupaten } \\
\text { Banjarnegara }\end{array}$ & $\begin{array}{c}\text { Rp. } \\
1.370 .000 .\end{array}$ \\
\hline 28 & $\begin{array}{l}\text { Kabupaten } \\
\text { Purbalingga }\end{array}$ & $\begin{array}{c}\text { Rp. } \\
1.522 .500 .\end{array}$ \\
\hline 29 & Kabupaten Batang & $\begin{array}{c}\text { Rp. } \\
1.603 .000 .\end{array}$ \\
\hline 30 & Kota Pekalongan & $\begin{array}{c}\text { Rp. } \\
1.623 .750 .\end{array}$ \\
\hline 31 & $\begin{array}{l}\text { Kabupaten } \\
\text { Pekalongan }\end{array}$ & $\begin{array}{c}\text { Rp. } \\
1.583 .697 .\end{array}$ \\
\hline 32 & $\begin{array}{l}\text { Kabupaten } \\
\text { Pemalang }\end{array}$ & $\begin{array}{c}\text { Rp. } \\
1.460 .000 .\end{array}$ \\
\hline 33 & Kota Tegal & $\begin{array}{c}\text { Rp. } \\
1.499 .500 .\end{array}$ \\
\hline 34 & Kabupaten Tegal & $\begin{array}{c}\text { Rp. } \\
1.487 .000 .\end{array}$ \\
\hline 35 & Kabupaten Brebes & $\begin{array}{c}\text { Rp. } \\
1.418 .100 .\end{array}$ \\
\hline
\end{tabular}

Sumber : Data primer diolah, 2018 
Bagi beberapa perusahaan kecil, pembayaran gaji karyawan belum sepenuhnya sesuai Upah Minimum Kabupaten (UMK) yang telah ditetapkan. Dari jumlah total karyawan hanya baru sekitar 30\% yang digaji sesuai UMK. Untuk mengatasi permasalahan tersebut, maka Kebijakan yang ditentukan oleh perusahaan adalah berupaya menaikkan upah bagi karyawan setiap tahunnya. Dari penelitian yang dilakukan, didapatkan bahwa hampir sebagian besar perusahaan di Kabupaten Kebumen. Beberapa perusahaan di Kabupaten Kebumen tidak mengalami kendala yang cukup berarti dalam membayar gaji karyawan sesuai dengan UMK yang telah ditetapkan. Namun bagi beberapa perusahaan kecil yang ada di Kabupaten Kebumen, kendala tentang implementasi UMK dalam pemberian gaji karyawan juga masih ada.
Dalam hal pengusaha tidak mampu membayar upah minimum, maka pengusaha dapat mengajukan penangguhan pelaksanaan upah minimum. (Pasal 2 Kepmenaker 231/2003) Penangguhan pelaksanaan upah minimum Bagi Perusahaan Yang Tidak Mampu dengan mekanisme sebagai berikut.

1. Setelah gubernur menetapkan UMK bagi perusahaan yang tidak mampu dapat mengajukan permohonan penangguhan Upah Minimum sesuai Keputusan Menteri Tenaga Kerja dan Transmigrasi Nomor. Kep. 231/MEN/2003 tentang Tata Cara Penangguhan Pelaksanaan Upah Minimum.

2. Permohonan penangguhan diajukan oleh pengusahan kepada Gubernur melalui instansi yang bertanggungn jawab di bidang ketenagakerjaan provinsi paling lambat 10 hari sebelum tanggal berlakunya UMK.

Gambar 1.

Prosedur Penangguhan UMK

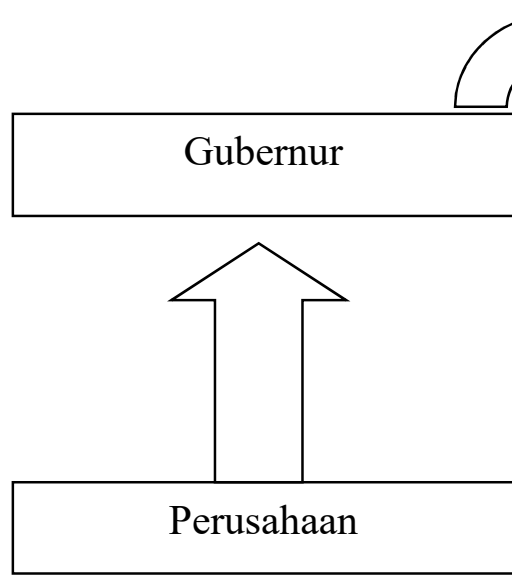

Syarat :

Ada kesepakatan secara bipartrit di perusahaan Lampiran :

1. Akte pendirian

2. Laporan Keuangan

3. Perkemb. Produksidan Pmasaran

4. Data Upah

5. Jumlah Pekerja

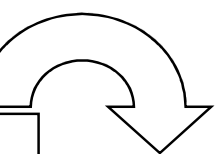

Tim Penangguhan

Koordinasi Disnaker

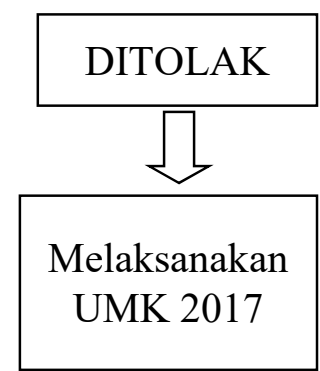

Sumber : Data primer diolah, 2018
DISETUJUI

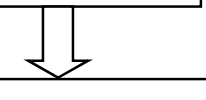

1. Sesuai dengan UM lama

2. Lebih tinggi UM lama dan lebih rendah UM baru

3. Menangguhkan UM baru secara bertahap 
Peran pemerintah dalam mengawasi pelaksanaan penggajian karyawan sesuai dengan UMK di Kabupaten Kebumen meliputi hal-hal sebagai berikut.

a. Pengawasan implementasi UMK langsung di bawah pengawasan pusat yang berada di setiap Provinsi. Untuk di Jawa Tengah Satuan Pengawasan Tenaga Kerja berada di Magelang.

b. Pembahas UMK adalah Dewan Pengupahan yang terdiri dari DISNAKERKOPUKM, Asosiasi Pengusaha Indonesia (APINDO), Akademisi, Serikat Pekerja Seluruh Indonesia (SPSI).

c. DISNAKERKOPUKM Kabupaten Kebumen melakukan fungsi sosialisasi dan pembinaan semua aturan ketenagakerjaan. Sedangkan untuk pelaksanaannya dari pengawas provinsi.

Gaji yang diterima oleh sebagian besar karyawan perusahaan di Kabupaten Kebumen sebenarnya hanya cukup untuk memenuhi kebutuhan sehari-hari. Namun jika untuk menciptakan kesejahteraan dari berbagai aspek kebutuhan baik primer, skunder dan tersier maka gaji sesuai UMK belum sepenuhnya mencukupi untuk pemenuhan kebutuhan tersebut.

Dari penelitian yang dilakukan didapatkan informasi bahwa informan yang terdiri dari pengusaha dan karyawan menyatakan bahwa program kesejahteraan fasilitas sudah sebagian besar terpenuhi. Namun belum semua indikator kesejahteraan fasilitas sudah bisa dipenuhi. Ratarata perusahaan memberikan fasilitas transportasi, parkir, dan fasilitas kesehatan. berdasarkan indikator kesejahteraan terutama pada aspek kesejahteraan ekonomis, maka hampir sebagian besar dari perusahaan yang diteliti dan karyawan yang diwawancarai menyatakan bahwa perusahaan telah memberikan tunjangan serta jaminan pemeliharaan kesehatan dan tunjangan lainnya.

Dalam hal pencapaian kesejahteraan pekerja, perusahaan hendaknya harus mampu memberikan gaji sesuai dengan Upah Minimum dan ditambah dengan pemberian berbagai tunjangan meliputi tunjangan berupa program kesejahteraan ekonomis, kesejahteraan fasilitas bagi karyawan, serta program kesejahteraan pelayanan. Jika perusahaan dapat menerapkan hal ini maka implementasi kebijakan pemberian Upah Minimum akan berpengaruh terhadap pencapaian kesejahteraan bagi pekerja pada khususnya dan bagi masyarakat pada umumnya.

\section{SIMPULAN DAN IMPLIKASI}

\section{Simpulan}

1. Berdasarkan hasil penelitian yang telah dilakukan di Kabupaten Kebumen hampir rata-rata perusahaan sudah menerapkan pembayaran gaji karyawan sesuai dengan ketentuan UMK, meskipun dalam implementasinya belum seratus persen. Meski Pemerintah Kabupaten Kebumen telah menetapkan Upah Minimum Kabupaten (UMK) tahun 2017 sebesar Rp 1.433.900,00 namun masih banyak pengusaha/perusahaan yang membayar gaji pegawainya dibawah UMK tersebut. Hal ini juga dikuatkan oleh kondisi pekerja di Kabupaten Kebumen, di mana seperti terdapat ketentuan tidak tertulis di Kabupaten Kebumen bahwa pekerja harus menerima begitu saja upah dari perusahaan tanpa ada hak untuk menuntut.

2. Hampir sebagian besar pengusaha di Kabupaten Kebumen mengetahui besaran UMK yang harus dibayarkan. Dan Besaran UMK tersebut (tahun 2017 Rp 1.433.900,00) menurut beberapa pengusaha sudah sesuai dengan apa yang mereka harapkan. Dari hasil penelitian beberapa perusahaan tidak mengalami kendala yang cukup berarti dalam membayar gaji karyawan sesuai dengan UMK yang telah ditetapkan.

3. Peran pemerintah daerah dalam implementasi UMK yang dilaksanakan oleh Fungsi Hubungan Industrial dan Syarat Kerja Dinas Tenaga Kerja Koperasi dan UKM (DISNAKERKOPUKM) Kabupaten Kebumen hanya sebatas sosialisasi dan pembinaan serta permasalahan yang terjadi pada perusahaan atau tenaga kerja di lingkup Kabupaten Kebumen. Wujud pembinaan yang dilakukan adalah sosialisasi ke perusahaan berkaitan dengan besaran UMK yang telah ditetapkan dan wajib diimplementasikan oleh perusahaan, kewajiban-kewajiban perusahaan kepada 
pekerja, yang diarahkan ke karyawan dan serikat pekerjanya. Pengawasan implementasi UMK langsung di bawah pengawasan pusat yang berada di setiap Provinsi. Untuk di Jawa Tengah Satuan Pengawasan Tenaga Kerja berada di Magelang.

4. Hampir sebagian besar dari perusahaan yang diteliti dan karyawan yang diwawancarai menyatakan bahwa perusahaan telah memberikan tunjangan serta jaminan selain memberikan gaji pokok. Tunjangan yang diberikan sangat beragam misalnya pemeliharaan kesehatan, transportasi, tunjangan menikah, tunjangan bagi karyawan yang sakit, dan sebagainya. Diterimanya program kesejahteraan secara ekonomis juga dirasakan oleh para karyawan perusahaan yang diteliti. Dari penelitian yang dilakukan didapatkan informasi bahwa informan yang terdiri dari pengusaha dan karyawan menyatakan bahwa program kesejahteraan fasilitas sudah sebagian besar terpenuhi. Namun belum semua indikator kesejahteraan fasilitas sudah bisa dipenuhi. Rata-rata perusahaan memberikan fasilitas transportasi, parkir, dan fasilitas kesehatan. Namun jika dikaitkan dengan pemenuhan kesejahteraan, implementasi UMK di Kabupaten Kebumen belum bisa dikatakan sudah dapat memenuhi kesejahteraan katyawan. Gaji yang diterima oleh sebagian besar karyawan perusahaan di Kabupaten Kebumen sebenarnya hanya cukup untuk memenuhi kebutuhan sehari-hari. Namun jika untuk menciptakan kesejahteraan dari berbagai aspek kebutuhan baik primer, skunder dan tersier maka gaji sesuai UMK belum sepenuhnya mencukupi untuk pemenuhan kebutuhan tersebut.

\section{Implikasi}

1. Perusahaan wajib mengimplementasikan pembayaran gaji bagi karyawannya sesuai dengan UMK yang telah ditetapkan. Hal ini sesuai dengan Peraturan Pemerintah No. 78 Tahun 2015 tentang Pengupahan. Bahwa untuk melaksanakan ketentuan Pasal 97 Undang-Undang Nomor 13 Tahun 2003 tentang Ketenagakerjaan, perlu menetapkan Peraturan Pemerintah tentang Pengupahan. UMK diterapkan dan berlaku bagi semua perusahaan tanpa melihat jumlah tenaga kerja yang ada pada perusahaan tersebut dan ketentuan pemberlakuan UMK sudah harus diterapkan oleh perusahaan sejak masa kerja karyawan 0 th (awal masuk kerja) dan harus lebih dari UMK setelah 1 tahun masa kerja.

2. Beberapa perusahaan yang diteliti tidak mengalami kendala dalam implementasi UMK sesuai yang telah ditetapkan, namun jika perusahaan mengalami kendala dalam hal mengimplementasikan pembayaran gaji karyawan sesuai UMK maka ada mekanisme penangguhan pembayaran. Ketika perusahaan tidak mampu memenuhi pembayaran gaji karyawan sesuai UMK maka harus ada penangguhan selama 3 (tiga) bulan jika selama masa penangguhan perusahaan tetap tidak bisa memenuhi pembayaran gaji sesuai UMK maka sudah menjadi kewenangan Satuan Pengawasan di Tingkat Provinsi untuk menindaklanjuti melalui nota pemeriksaan dan jika perusahaan tetap tidak sanggup memenuhi maka ada ancaman pidana karena telah melanggar Undang Undang tentang Tenaga Kerja dan peraturan pemerintah tentang Pengupahan.

3. Dibutuhkan peran pemerintah secara nyata dan tegas dalam mengawal implementasi kebijakan pemberian Upah Minimum bagi karyawan perusahaan sebagai fungsi kontrol mulai dari sosialisasi kepada perusahaan maupun pekerja, serta pemberian bantuan masukan dalam penyelesaian permasalahan yang dialami perusahaan terutama dalam hal pengupahan, sehingga diharapkan upah minimum dapat diterapkan di semua perusahaan dengan baik.

4. Dalam hal pencapaian kesejahteraan pekerja, perusahaan hendaknya harus mampu memberikan gaji sesuai dengan Upah Minimum dan ditambah dengan pemberian berbagai tunjangan meliputi tunjangan berupa program kesejahteraan ekonomis, kesejahteraan fasilitas bagi karyawan, serta program kesejahteraan pelayanan. Jika 
perusahaan dapat menerapkan hal ini maka implementasi kebijakan pemberian Upah Minimum akan berpengaruh terhadap pencapaian kesejahteraan bagi pekerja pada khususnya dan bagi masyarakat pada umumnya.

\section{DAFTAR PUSTAKA}

Dunn, William N. 2003. Analisis Kebijakan Publik. Yogyakarta: Gadjah Mada University Press.

Anderson, James E. 1979. Public Policy Making. Boston: Houghton Mifflin.

Winarno, Budi. 2002. Teori dan Proses Kebijakan Publik. Yogyakarta: Media Pressindo.

Winarno, Budi. 2007. Kebijakan Publik: Teori dan Proses. Yogyakarta: Media Pressindo.

Widodo, Joko. 2001. Good Governance Telaah Dari Dimensi Akuntabilitas, Kontrol Birokrasi Pada Era Desentralisasi dan Otonomi Daerah. Surabaya: Insan Cendekia.

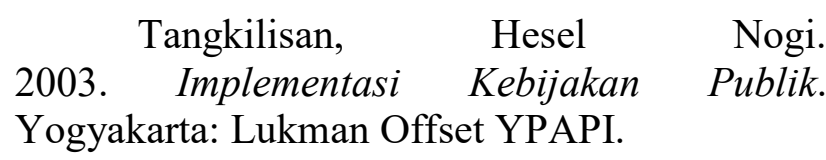

Tangkilisan, Hesel Nogi. 2003. Kebijakan Publik Yang Membumi. Yogyakarta: Lukman Offset YPAPI.

Undang Undang No. 13 Tahun 2003 tentang Ketenagakerjaan pasal 88 ayat (4) jo 89

Peraturan Pemerintah No. 78 tahun 2015 tentang pengupahan yang diundangkan pada tanggal 23 Oktober 2015

Peraturan menteri tenaga kerja dan transmigrasi nomor 7 tahun 2013 tentang upah minimum

Peraturan menteri ketenagakerjaan no. 1 tahun 2017 tentang struktur dan skala upah

Peraturan gubernur jawa tengah nomor. 560/3 tahun 2016

Peraturan Menteri Tenaga Kerja dan Transmigrasi RI Nomor 7 Tahun 2013 tentang Upah Minimum.
Peraturan Menteri Tenaga Kerja dan Transmigrasi RI Nomor 13 Tahun 2012 tentang Komponen dan Pelaksanaan Tahapan Pencapaian Kebutuhan Hidup Layak.

Keputusan Presiden RI Nomor 107 Tahun 2004 tentang Dewan Pengupahan.

Peraturan Pemerintah Republik Indonesia Nomor 78 Tahun 2015 Tentang Pengupahan

Undang-Undang Republik Indonesia Nomor 13 Tahun 2003 Tentang Ketenagakerjaan

http://www.hukumonline.com/klinik/det ail/1t50b81d32ad45d/penangguhan-pelaksanaanupah-minimum-bagi-perusahaan-tidak-mampu

Aulia Milano, Tahun 2016, Politik Hukum Pengupahan : Suatu Kajian Terhadap Penetapan Upah Minimum Kabupaten (UMK) 